\title{
Detection of Single Base Mutation Causing Drug-resistance in Leukemia Gene by PNA-directed Clamping PCR
}

\author{
Kkothanahreum Park, ${ }^{a}$ Woong Jung, ${ }^{\dagger, a}$ Bo-Ra Choi, ${ }^{\ddagger}$ Heekyung Park, ${ }^{\ddagger}$ and Dong-Eun Kim ${ }^{*}$ \\ Department of Bioscience and Biotechnology, WCU program, Konkuk University, Seoul 143-701, Korea \\ *E-mail:kimde@konkuk.ac.kr \\ ${ }^{\dagger}$ Department of Emergency Medicine, East-West Neo Medical Center, Kyung Hee University, Seoul 134-727, Korea \\ †ANAGENE Inc. 816 Tamnip-dong, Yuseong-gu, Daejeon 305-510, Korea \\ Received May 7, 2010, Accepted May 25, 2010
}

Key Words: Single nucleotide polymorphism (SNP), Peptide nucleic acid (PNA), Clamping PCR, Complementary DNA (cDNA)

Single nucleotide polymorphisms (SNPs) are one base sequence variations that cause various complex traits in diseases and become an important tool for pharmacogenomics. ${ }^{1,2}$ Since detection of SNPs in the human genome is highly demanded, many methods that are compatible with the clinical use of molecular diagnostics have been developed to date, including allele specific priming of the polymerase chain reaction (PCR), ligase amplification reaction, ${ }^{5}$ and extended DNA primers analysis by mass spectrometry. ${ }^{6}$ To obtain the reliable sensitivity of these methods, the target nucleic acids are often amplified to detectable quantities by PCR. Particularly, primer extension with allele-specific termination is the most commonly used method in conjunction with mass spectrometric detection. ${ }^{7}$

Although PCR itself has been used to detect SNPs by using allele specific oligonucleotide primers, most of DNA primertemplate mismatches have no significant difference in PCR process with a similar amount of amplification regardless of mismatches. ${ }^{8}$ Similar to oligodeoxynucleotides as amplification primers that are specifically complementary to the target DNA sequence, PNA (Peptide Nucleic Acid, Fig. 1A) has been observed to be a potent DNA mimic in sequence-specific hybridization. ${ }^{9}$ It has been shown that PNA/DNA duplexes are more stable than the corresponding DNA/DNA duplex by $1{ }^{\circ} \mathrm{C}$ per base pair at physiological condition. ${ }^{10-12}$ More importantly, it has been observed that the single base pair mismatch is better discriminated with PNA/DNA than with the corresponding DNA/DNA. ${ }^{10-12}$ Thus, it has been reported that PCR can be blocked with oligoPNA in a sequence-specific manner, utilizing the properties of PNA as stringent complementary nucleic acids for DNA along with the fact that PNA cannot be used as extending primers for DNA polymerization. ${ }^{9}$ This attempt coined as 'clamping PCR' has been devised to discern two alleles which differ by only one base pair in DNA sequence. Thus, this technique allows us to identify a SNP caused by base pair mismatch with PCR. ${ }^{9}$

Chronic myelogenous leukemia (CML) is a myeloproliferative disorder that is associated with Philadelphia chromosome carrying the chimeric $B C R / A B L$ oncogene generated by a reciprocal translocation between chromosomes 9 and $22, \mathrm{t}(9 ; 22) .{ }^{13,14}$

${ }^{\mathrm{a}}$ These authors equally contributed to this study.
A targeted therapy against the chimeric Bcr-Abl tyrosine kinase as an anti-leukemic drug, imatinib mesylate (STI571, Gleevec ${ }^{\circledR}$, Novartis Pharmaceuticals Corp.) that is a competitive inhibitor at ATP binding site of Bcr-Abl tyrosine kinase, is currently available and considered a first-line agent for newly diagnosed CML. ${ }^{15-17}$ However, despite its impressive efficacy, disease relapse has been observed after initial response to imatinib. ${ }^{18,19}$ Drug-resistance during imatinib treatment is mostly related to point mutations occurring within the kinase domain of Bcr-Abl at more than 40 different amino acid positions. ${ }^{20}$ Among those SNPs, the T315I mutant of Bcr-Abl, threonine (T) in position 315 is substituted with isoleucine (I) due to a single base change $(\mathrm{C} \rightarrow \mathrm{T})$, has been reported to show resistance to imatinib without other alternative therapy. ${ }^{15}$

We present here an efficient PNA-directed clamping PCR

(A)

(B)

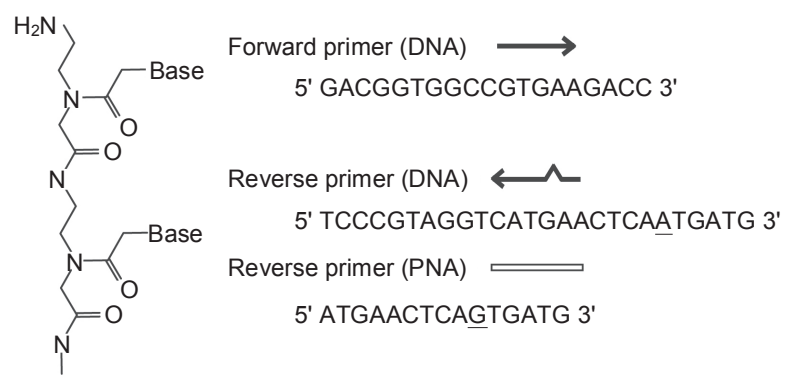

(C)

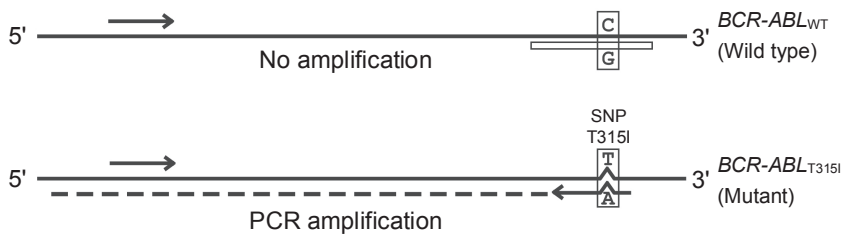

Figure 1. (A) Chemical structure of PNA. (B) Sequences of the reverse primer, forward primer, and PNA. Each underlined nucleotide is the location of T315I SNP. (C) Schematic representation of PNA-directed PCR clamping. Top figure shows Bcr-Abl ${ }_{\mathrm{WT}}$ (wild type) template DNA bound with PNA, resulting in no amplification due to PCR clamping with PNA. Bottom figure demonstrates PCR amplification of Bcr$\mathrm{Abl}_{\mathrm{T} 315 \mathrm{I}}$ (mutant) template containing T315I mutation. 
(A)

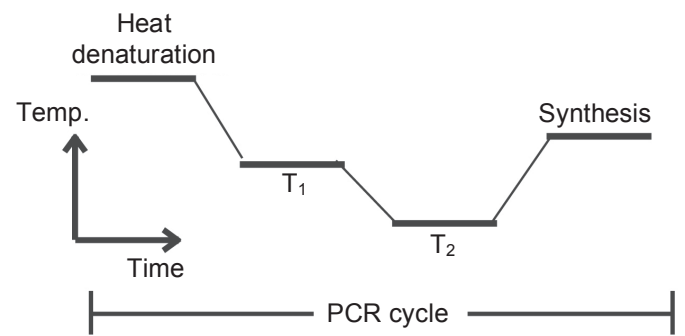

(C)

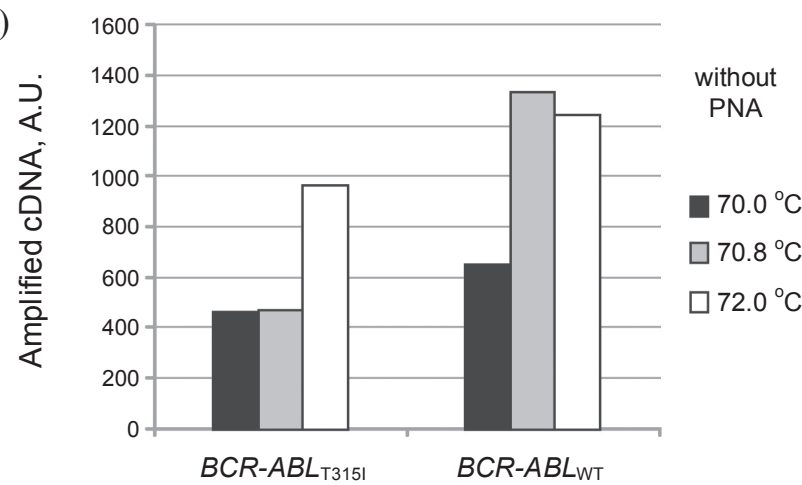

(B)

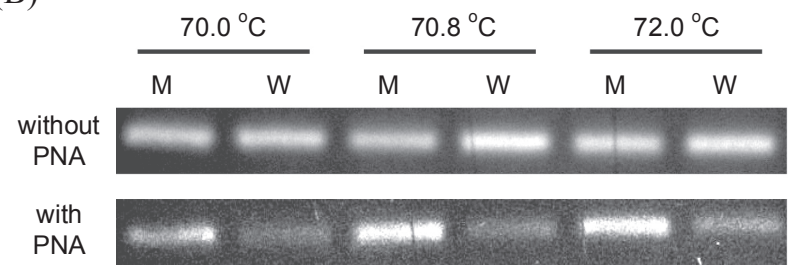

(D)

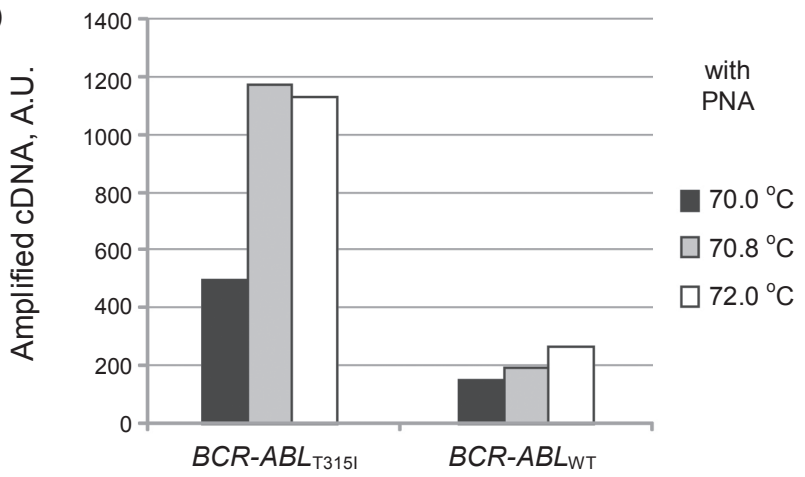

Figure 2. (A) Schematic representation of the PCR cycle profile used in PNA-directed clamping PCR. T1: temperature of PNA annealing step $(20 \mathrm{sec})$, T2: temperature of PCR primer annealing step $(20 \mathrm{sec})$. (B) Optimization of T1 for efficient PNA-directed PCR clamping. cDNA was PCR amplified (M: mutant, Bcr-Abl ${ }_{\mathrm{T} 315 \mathrm{I}}$, W: wild type, Bcr-AblwT) with or without PNA. (C) \& (D) show amounts of PCR products produced at three different temperatures without and with PNA, respectively. A.U.; arbitrary unit.

method to quantitatively detect the amount of cellular RNAs harboring the Abl gene of T315I point mutation conferring the drug-resistance. This method allows us to discriminate and quantify the amount of mixed alleles which differ by only one base pair. Instead of using synthetic DNA as a model template for SNP detection, we used two cell lines that contain the BCRABL chimeric gene but differ by one base pair for T315I point mutation, and their RNAs were extracted and used as samples for SNP detection. Hence, the method developed here will be readily applicable to a diagnostics measurement of the relative amount of the drug-resistant leukemic cells present in patients' bone marrow.

In order to block PCR at the priming site with PNA, oligoPNA was designed to bind only to the sequence of wild type not to the T315I mutant that is perfectly matched by the reverse PCR primer (Fig. 1B). Because PNA has a higher thermal stability of a PNA/DNA duplex compared to the corresponding DNA/DNA duplex, length of oligoPNA was designed to be shorter than the reverse primer oligoDNA to give a similar melting temperature $\left(\sim 67^{\circ} \mathrm{C}\right)$. The mismatched base (T in BCR$\mathrm{ABL}_{\mathrm{T} 315 \mathrm{I}}$ template) in the oligoPNA (underlined nucleotide, G) has been determined to locate at the 6th nucleotide from the 3 '-end to give about $10{ }^{\circ} \mathrm{C}$ difference of melting temperature, compared with the perfect match (i.e., oligoPNA binding to BCR-ABL ${ }_{w T}$ template). ${ }^{21}$ Taking advantage of superb base discrimination capability of PNA, we designed the reaction scheme of PNA-directed clamping PCR (Fig. 1C), in which the PNA must compete effectively against its cognate PCR primer in binding to their common recognition site. Thus, the oligoDNA that binds to $\mathrm{T} 315 \mathrm{I}$ point mutation ( $\mathrm{T}$ in $\mathrm{BCR}-\mathrm{ABL}_{\mathrm{T} 315 \mathrm{I}}$ template) can generate the amplified PCR products, whereas the oligoPNA that binds preferentially to the wild type template cannot produce PCR amplification.

To facilitate PNA annealing to the perfectly matched wild type template, the normal 3 step PCR cycle was expanded with a PNA annealing step between the heat denaturation and the PCR primer annealing step (Fig. 2A). During this step at a temperature higher than the step of PCR primer annealing, only PNA will be allowed to bind to its target sequence. Figure 2B shows an experimental result of a PCR clamping experiment at three different PNA annealing temperatures either in the presence or in the absence of oligoPNA. Two cDNA templates for PCR amplification were prepared by reverse transcribing the RNAs extracted from two cell lines; the one containing the $B C R / A B L$ without T315I SNP (wild type, W) and the other containing the $B C R / A B L$ with T315I SNP (mutant, M). Although the PCR primer was predicted to only amplify the cDNA obtained from the mutant in the absence of PNA, it was not able to discriminate single base mismatch at the elevated temperatures $\left(70 \sim 72{ }^{\circ} \mathrm{C}\right)$ by showing comparable amounts of amplified DNAs in both mutant and wild type cDNA (Fig. 2B \& C). However, in the presence of PNA, PCR clamping was effectively observed in the wild type cDNA template (Fig. 2B \& D). These results indicate that at an elevated temperature for PNA annealing the PCR primer was unable to bind to the mismatched template DNA (wild type, $\mathrm{W}$ ) with PCR clamping by the annealed PNA. Temperature of $70.8^{\circ} \mathrm{C}$ provides a stark difference in the amounts of PCR amplification by 6-fold due to the PCR clamping. Therefore, this temperature was chosen to explore further the PCR clamping by PNA. 
(A)

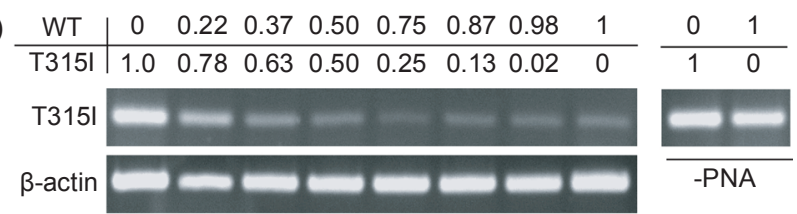

(B)

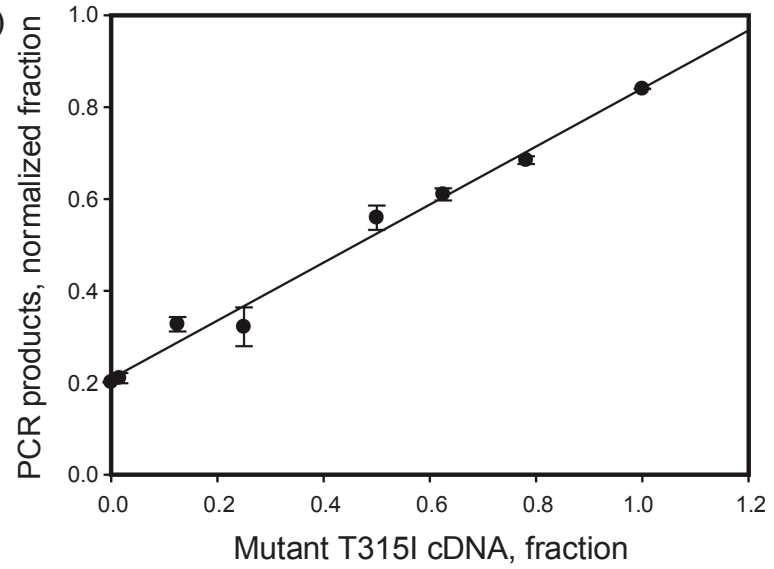

Figure 3. (A) Quantitative discrimination of one-base mismatch with PNA-directed PCR clamping. Shown is the gel image of PCR clamping as the mixing ratios of T315I mutant decreased. Mixed cDNAs (wild type and T315I mutant) at different ratios were subjected to PNA-directed clamping PCR. As a loading control, a $330 \mathrm{bp}$ fragment of $\beta$-actin cDNA was PCR amplified under the same condition using the mixed cDNAs from each mixture. (B) T315I cDNA shown in the gel was quantified and normalized against the loading control. Standard curve shows a linear relationship between mixing fractions of single-base mismatched cDNA (T315I) with PNA and the amount of T315I PCR products; $\mathrm{R}^{2}=0.993$ and $n=3$ for each measurement.

We next carried out an experiment to test whether the method would be able to quantitatively discriminate between the wild type and the mutant targets differing by one base mismatch in a mixed target PCR, in which both targets were present in the PCR reaction mixture. The mixed PCR targets were prepared by mixing cDNAs at different ratios, which were transcribed from RNAs extracted from both wild type and mutant cells. As shown in Fig. 3A, in the presence of both reverse DNA primer and oligoPNA the amount of PCR product was decreased as the relative concentration of wild type cDNA increased. It indicates that a single base mismatch in the reverse primer/ DNA (wild type) was replaced with the perfect matched PNA/ DNA duplex showing the PCR clamping in a dose-dependent manner. Importantly, the linear relationship $\left(\mathrm{R}^{2}=0.993\right)$ between the amounts of perfect matched PNA/template DNA duplex and the extent of PCR clamping was observed in our experimental set-up (Fig. 3B). It is interesting to note that as much as $20 \%$ of the target sequences can escape clamping with detectable PCR products even at zero concentration of mismatched template DNA (mutant type), as shown in the y-intercept.

To our knowledge, our study is the first demonstration of quantitative analysis of target DNA templates differing by one base mismatch with the PNA-directed PCR clamping method. Thus, this PNA-directed PCR clamping method could be used to measure the relative abundance of drug-resistant leukemic cells in total hematopoietic cells obtained from leukemia patients. Furthermore, the PCR clamping method illustrated in our study will be applicable to detect any SNPs present in human genome by precisely designing the size of the PNA and PCR primers and/or altering their exact positions on the target DNA.

\section{Experimental Section}

Cell culture. The murine pro-B lymphoid cell lines BaF3/ $\mathrm{Bcr}-\mathrm{Abl}$ and $\mathrm{BaF} 3 / \mathrm{Bcr}_{-} \mathrm{Abl}_{\mathrm{T} 315 \mathrm{I}}$ that could express wild type $\mathrm{Abl}$ and mutant $\mathrm{Abl}$ (T315I, SNP), respectively, were cultured in RPMI1640 medium (WelGene Biopharmaceuticals, Daegu, Korea), supplemented with heat inactivated $10 \%$ fetal bovine serum (FBS) (WelGene) and 1\% antibiotics (100 U/mL penicillin $\mathrm{G}$ and $100 \mu \mathrm{g} / \mathrm{mL}$ streptomycin) (WelGene) at $37{ }^{\circ} \mathrm{C}$ in humidified 5\% $\mathrm{CO}_{2}$ atmosphere.

Reverse transcription for cDNA synthesis. Total RNAs from $\mathrm{BaF} 3 / \mathrm{Bcr}-\mathrm{Abl}$ cell and $\mathrm{BaF} 3 / \mathrm{Bcr}-\mathrm{Abl}_{\mathrm{T} 315 \mathrm{I}}$ cell were isolated by using the easy-BLUE ${ }^{\mathrm{TM}}$ total RNA extraction kit system (Intron Biotechnology, Seoul, Korea) according to the manufacturer's instructions. Concentrations of RNA samples were measured with a spectrophotometer to determine the OD260 and OD260/280 values. Total RNA $(2 \mu \mathrm{g})$ was subjected to reverse transcription (RT) in a volume of $20 \mu \mathrm{L}$ to synthesize the first-strand cDNA using Oligo-dT Maxime Reverse Transcription premix kit (Intron) according to the manufacturer's instruction.

PNA-directed clamping PCR. Reverse and forward primers (Fig. 1B) were chemically synthesized by conventional DNA synthesis (Cosmo Gentech, Seoul, Korea) and OligoPNA (Fig. 1B) was purchased from PANAGENE Inc. (Daejeon, Korea). PCR amplification was performed with $5 \mu \mathrm{L}$ of the cDNA products in a total volume of $20 \mu \mathrm{L}$ containing $2.5 \mathrm{U}$ Taq DNA polymerase, $2.5 \mathrm{mM}$ dNTPs, PCR buffer (50 mM TrisHCl, pH 7.2 and $75 \mathrm{mM} \mathrm{KCl}), 1.25 \mu \mathrm{M}$ of each primer and/or oligoPNA. PCR cycling after initial denaturation at $94^{\circ} \mathrm{C}$ for 2 min was as follows: $20 \mathrm{sec}$ at $94^{\circ} \mathrm{C}, 20 \mathrm{sec}$ at $70 \sim 72{ }^{\circ} \mathrm{C}, 20 \mathrm{sec} 66^{\circ} \mathrm{C}$, and $30 \mathrm{sec}$ at $72{ }^{\circ} \mathrm{C}$ for total of 35 cycles followed by $5 \mathrm{~min}$ final extension at $72{ }^{\circ} \mathrm{C}$.

Gel electrophoresis and PCR product quantification. Amplified PCR products were monitored by electrophoresis in 3\% $(\mathrm{v} / \mathrm{v})$ agarose gel, stained with ethidium bromide, and photographed under ultraviolet (UV) transillumination. Amount of PCR products were quantified by densitometric analysis of the photographed gels using Gel-Pro analyzer software (Gel-Pro, Image Database for Windows, Silver Spring, MD). Standard curve (Fig. 3B) for quantification of mutant cDNA was constructed by normalizing the amount of T315I PCR products against the $\beta$-actin internal control (PCR product $/ \beta$-actin). Each experiment was repeated three times to ensure reproducibility.

Acknowledgments. This work was supported by a grant from the National Research Foundation of Korea through the general research grant (2009-0071058) and a grant (20080401 034026) from the BioGreen 21 Program, Rural Development Administration, Republic of Korea. 


\section{References}

1. Syvanen, A. C. Nat. Genet. 2005, 37 Suppl, S5.

2. McCarthy, J. J.; Hilfiker, R. Nat. Biotechnol. 2000, 18, 505.

3. Wu, D. Y.; Ugozzoli, L.; Pal, B. K.; Wallace, R. B. Proc. Natl. Acad. Sci. USA 1989, 86, 2757.

4. Saiki, R. K.; Walsh, P. S.; Levenson, C. H.; Erlich, H. A. Proc. Natl. Acad. Sci. USA 1989, 86, 6230

5. Wu, D. Y.; Wallace, R. B. Genomics 1989, 4, 560.

6. Landegren, U.; Nilsson, M.; Kwok, P. Y. Genome Res. 1998, 8, 769.

7. Griffin, T. J.; Smith, L. M. Trends Biotechnol. 2000, 18, 77.

8. Kwok, S.; Kellogg, D. E.; McKinney, N.; Spasic, D.; Goda, L.; Levenson, C.; Sninsky, J. J. Nucleic Acids Res. 1990, 18, 999.

9. Orum, H.; Nielsen, P. E.; Egholm, M.; Berg, R. H.; Buchardt, O.; Stanley, C. Nucleic Acids Res. 1993, 21, 5332.

10. Egholm, M.; Buchardt, O.; Christensen, L.; Behrens, C.; Freier, S. M.; Driver, D. A.; Berg, R. H.; Kim, S. K.; Norden, B.; Nielsen, P. E. Nature 1993, 365, 566.

11. Nielsen, P. E.; Egholm, M.; Berg, R. H.; Buchardt, O. Science 1991, 254, 1497

12. Nielsen, P. E.; Egholm, M.; Berg, R. H.; Buchardt, O. Anticancer Drug Des. 1993, 8, 53.
13. Daley, G. Q.; Van Etten, R. A.; Baltimore, D. Science 1990, 247 , 824.

14. Faderl, S.; Talpaz, M.; Estrov, Z.; O'Brien, S.; Kurzrock, R.; Kantarjian, H. M. N. Engl. J. Med. 1999, 341, 164.

15. Steinberg, M. Clin. Ther. 2007, 29, 2289.

16. Druker, B. J.; Talpaz, M.; Resta, D. J.; Peng, B.; Buchdunger, E.; Ford, J. M.; Lydon, N. B.; Kantariian, H.; Capdeville, R.; OhnoJones, S.; Sawyers, C. L. N. Engl. J. Med. 2001, 344, 1031.

17. Tsao, A. S.; Kantarijian, H.; Talpaz, M. Br. J. Haematol. 2002, $119,15$.

18. Bradeen, H. A.; Eide, C. A.; O'Hare, T.; Johnson, K. J.; Willis, S. G.; Lee, F. Y.; Druker, B. J.; Deininger, M. W. Blood 2006, 108, 2332.

19. Gorre, M. E.; Mohammed, M.; Ellwood, K.; Hsu, N.; Paquette, R.; Rao, P. N.; Sawyers, C. L. Science 2001, 293, 876.

20. Hughes, T.; Deininger, M.; Hochhaus, A.; Branford, S.; Radich, J.; Kaeda, J.; Baccarani, M.; Cortes, J.; Cross, N. C.; Druker, B. J.; Gabert, J.; Grimwade, D.; Hehlmann, R.; Kamel-Reid, S.; Lipton, J. H.; Longtine, J.; Martinelli, G.; Saglio, G.; Soverini, S.; Stock, W.; Goldman, J. M. Blood 2006, 108, 28.

21. Jensen, K. K.; Orum, H.; Nielsen, P. E.; Norden, B. Biochemistry 1997, 36, 5072. 